\title{
Changing Patterns of H6 Influenza Viruses in Hong Kong Poultry Markets
}

\author{
Hiroichi Ozaki, ${ }^{1}$ Yi Guan, ${ }^{2}$ Malik Peiris, ${ }^{2}$ Robert Webster, ${ }^{3}$ and Richard Webby ${ }^{3}$ \\ ${ }^{1}$ Laboratory of Veterinary Microbiology, Faculty of Agriculture, Tottori University, Tottori 680-8553, Japan \\ ${ }^{2}$ Department of Microbiology, The University of Hong Kong, Pokfulan, Hong Kong \\ ${ }^{3}$ Division of Virology, Department of Infectious Diseases, St. Jude Children's Research Hospital, Memphis, TN 38105, USA
}

Correspondence should be addressed to Hiroichi Ozaki, ikazo-h@muses.tottori-u.ac.jp

Received 7 July 2010; Accepted 13 September 2010

Academic Editor: Eric C. J. Claas

Copyright ( 2011 Hiroichi Ozaki et al. This is an open access article distributed under the Creative Commons Attribution License, which permits unrestricted use, distribution, and reproduction in any medium, provided the original work is properly cited.

\begin{abstract}
Until 2001, H6N1 influenza viruses in the Hong Kong bird markets were represented by a single stable A/teal/Hong Kong/W312/97like lineage. Beginning in 2001, despite a reduction in overall prevalence, an increase was observed in the number of H6 viruses isolated from chickens and other hosts. To assess any changes in H6 viruses, we characterized 18 H6 viruses isolated in the Hong Kong bird markets from 2001 to 2003. Experimental data showed that the 2003 H6 viruses had similar infectivity for chickens as did A/teal/HK/W312/97, and they were unable to transmit. Although all hemagglutinin genes were closely related to A/teal/HK/W312/97, 7 isolates were reassortant viruses containing similar gene segments of co-circulating H9N2 or H5N1 viruses. The receptor specificity was different from that of A/teal/Hong Kong/W312/97. Interestingly, similar observations have been documented in H9N2 viruses in Hong Kong. This evolution strongly suggests that some change in the ecology of influenza in the region selected for these changes. Taken together, these findings suggest that the H6 influenza viruses isolated in the Hong Kong markets are not well adapted to chickens and that the likely continued source of these viruses are other "minor" poultry species in which they are undergoing genetic and biologic evolution.
\end{abstract}

\section{Introduction}

The introduction and subsequent sustained global spread in the human population of influenza A viruses with a novel hemagglutinin (HA) subtype leads to an influenza pandemic. The novel influenza pandemics that occurred during the last century resulted in considerable mortality and morbidity. Genetic investigations revealed that these pandemic strains were partially or entirely derived from viruses of avian origin [1-4] and that most of them first appeared in southern China, a hypothetical influenza epicenter [5].

The avian $\mathrm{H} 5 \mathrm{~N} 1$ influenza virus that infected poultry and humans in Hong Kong in 1997 caused the death of 6 of 18 persons that were confirmed infected with this virus [6-8]. This virus was proposed to be a naturally occurring avian virus produced by the reassortment of $\mathrm{H} 5 \mathrm{~N} 1$ and $\mathrm{H} 9 \mathrm{~N} 2$ or H6N1 viruses [6, 7].

H9N2 influenza viruses have become panzootic during the last decade and have been isolated from different types of terrestrial poultry worldwide [9-11]. Two distinct lineages of H9N2 viruses, represented by the prototype A/duck/Hong Kong/Y280/97 (H9N2) (Dk/HK/Y280/97) and A/quail/Hong Kong/G1/97 (H9N2) (Qa/HK/G1/97) viruses, have become established in terrestrial poultry: Dk/HK/Y280/97-like viruses are found predominantly in chickens whereas Qa/HK/G1/97-like viruses are most often found in quail $[10,12]$. The Qa/HK/G1/97-like viruses are thought to have been involved in the generation of the highly pathogenic H5N1 virus first isolated in 1997 [12]. H9N2 viruses of each lineage have been isolated from humans $[13,14]$, and the Dk/HK/Y280/97-like lineage also has been isolated from pigs in southern China [15].

During 1997, an H6N1 influenza A virus, A/teal/Hong Kong/W312/97 was isolated from a green-winged teal [16]. Subsequent characterization of the virus showed that seven of its eight gene segments were closely related to those of the H5N1 influenza viruses isolated from humans in 1997 [6-8, 17]. Later studies showed that A/teal/Hong Kong/W312/97like viruses continued to circulate in the Hong Kong livebird markets and that all $\mathrm{H} 6 \mathrm{~N} 1$ viruses isolated up until 
2000 belonged to this lineage [18]. Similarly, the host range of these $\mathrm{H} 6 \mathrm{~N} 1$ viruses remained stable, with most isolates originating from quail and "minor" poultry species such as chukka, pheasant, and guinea fowl but rarely originating from chickens. Beginning in 2001, the host range appeared to be changing, with an increase in the number of H6N1 viruses isolated from chicken and silky chicken. To address whether this phenomenon was real and, if so, whether it was due to a change in the $\mathrm{H} 6 \mathrm{~N} 1$ viruses circulating in the markets, we investigated the antigenic, genetic, and biologic characteristics of various H6 influenza viruses isolated from the Hong Kong live-bird markets between 2001 and 2003. This paper describes the results of these studies and demonstrates an abrupt increase in the genetic diversity of $\mathrm{H} 6$ viruses in these markets.

\section{Materials and Methods}

2.1. Viruses. The viruses isolated in the Hong Kong region and the abbreviations used in this study are listed in Table 1. The viruses were collected from January 2001 through April 2003. Viruses present in fecal and cloacal samples from various bird species were grown in 10- to 11-day-old embryonated chicken eggs.

2.2. Antigenic Analysis. The H6 virus antigens were compared by using the hemagglutination inhibition (HI) test as previously described in [19]. All sera were pretreated with the receptor-destroying enzyme from Vibrio cholerae (Denka Seiken, Tokyo) to abolish interference by nonspecific serum inhibitors. The viruses, which came directly from infected allantoic fluid, were diluted to doses equivalent to four HA units for use in the tests.

2.3. RNA Extraction, RT-PCR, and DNA Sequencing. Viral RNA was extracted from infected allantoic fluid by using RNeasy kits (Qiagen, Valencia, CA) according to the manufacturer's instructions. Reverse transcription and PCR were performed under standard conditions by using primers specific for the various genes of influenza viruses [20]. PCR products were purified by using a gel extraction kit (Qiagen). Sequencing reactions were performed by the staff of the Hartwell Center for Bioinformatics and Biotechnology at St. Jude Children's Research Hospital. Template DNA was sequenced by using dRhodamine dye terminator cycle sequencing ready reaction kits with AmpliTaq DNA polymerase FS (Perkin-Elmer Applied Biosystems, Inc. [PE/ABI], Foster City, CA) and synthetic oligonucleotides. Samples were subjected to electrophoresis, detection, and analysis on PE/ABI model 3700 DNA sequencing instruments.

2.4. DNA Sequence Analysis. DNA sequences were compiled and edited by using the Lasergene sequence analysis software package (DNASTAR, Madison, WI). Multiple sequence alignments were made by using CLUSTAL W [21], and phylogenetic trees were generated by using the neighbor-joining algorithm in the TreeView version 1.6.6 software package (available at http://taxonomy.zoology.gla.ac.uk/rod/treeview .html). Nucleotide and amino acid sequences of other influenza viruses were obtained from the Influenza Sequence Database of the Los Alamos National Laboratory [22].

2.5. Hemagglutination Assays. The ability of the $\mathrm{H} 6$ viruses to hemagglutinate chicken, horse, and guinea pig erythrocytes was determined as previously described in [23]. Briefly, 32 HA units of virus (as determined by binding to chicken erythrocytes) were used in a hemagglutination assay with $0.5 \%(\mathrm{~V} / \mathrm{V})$ horse or guinea pig red blood cells. End titers were determined after one-hour incubation at room temperature. Chicken and guinea pig erythrocytes contain both $\alpha 2-3$ - and $\alpha 2-6$-linked sialic acid whereas those from horse contain almost exclusively $\alpha 2-3$ linkages [24], thereby indirectly inferring receptor preferences of the agglutinating viruses.

2.6. Growth of Viruses in Quail and Chickens. We used 5to 6-week-old Japanese quail and white leghorn chickens to determine the $50 \%$ infectious doses $\left(\mathrm{QID}_{50}\right.$ and $\left.\mathrm{CID}_{50}\right)$ of a selection of $\mathrm{H} 6$ viruses. Infectious allantoic fluid 10-fold serially diluted $\left(1: 10\right.$ to $\left.1: 10^{8}\right)$ was intranasally administered to three quails $(0.2 \mathrm{ml}$ inoculum $)$ or chickens $(0.5 \mathrm{ml}$ inoculum) of each group. Birds were examined daily for disease signs, and cloacal and tracheal swabs were taken 3 and 5 days after inoculation. Tracheal swabs were placed in $0.5 \mathrm{ml}$ of sample medium (50\% glycerol in phosphate-buffered saline (PBS) that contained $1000 \mathrm{U} / \mathrm{ml}$ penicillin, $200 \mu \mathrm{g} / \mathrm{ml}$ streptomycin, $50 \mathrm{U} / \mathrm{ml}$ mycostatin, $100 \mathrm{U} / \mathrm{ml}$ polymyxin $\mathrm{B}$, and $250 \mu$ g gentamicin); cloacal swabs were placed in $1 \mathrm{ml}$ of sample medium. Each of two embryonated chicken eggs were inoculated with $100 \mu \mathrm{l}$ of the sample medium containing tracheal or cloacal swabs and were incubated for 48 hours at $37^{\circ} \mathrm{C}$. HA assays using chicken red blood cells were performed to verify virus growth in the harvested allantoic fluid [19].

Transmission experiments were performed by following the method of Perez et al. [25]. Briefly, uninfected birds were placed in direct contact with or in cages above and below the inoculated birds $\left(10^{5}\right.$ pfu per bird) 1 day after inoculation. Trays between the cages were removed to allow efficient aerosol and fecal transmission. Animal work was performed under ABSL3+ biosafety conditions at St. Jude Children's Research Hospital.

\section{Results}

3.1. H6 Influenza Viruses from Poultry in Hong Kong. Intensive surveillance systems in the Hong Kong live-bird markets have been in place since 1997. From 2001 through 2003, these systems showed that 253 isolates of 42495 tested specimens were H6 influenza viruses (232 in 2001, 12 in 2002, and 9 in 2003). We arbitrarily selected 18 H6 influenza viruses isolated from domestic poultry for further study (Table 1).

3.2. Antigenic Analysis. Since 1997, H5 viruses in Hong Kong have undergone antigenic and genetic change. To 
TABLE 1: H6 influenza viruses characterized in this study.

\begin{tabular}{|c|c|c|c|}
\hline Group & Isolate $^{\mathrm{a}}$ & Subtype & Abbreviation \\
\hline \multirow{10}{*}{2001 isolates } & A/quail/HK/FB611/01 & $\mathrm{H} 6 \mathrm{~N} 1$ & $\mathrm{Qa} / \mathrm{HK} / \mathrm{FB} 611 / 01$ \\
\hline & A/quail/HK/FB801/01 & H6N1 & $\mathrm{Qa} / \mathrm{HK} / \mathrm{FB} / 801 / 01$ \\
\hline & A/quail/HK/SF104/01 & H6N1 & Qa/HK/SF104/01 \\
\hline & A/quail/HK/FY119/01 & H6N1 & Qa/HK/FY119/01 \\
\hline & A/quail/HK/NT342/01 & H6N1 & Qa/HK/NT342/01 \\
\hline & A/quail/HK/CSW106/01 & H6N1 & $\mathrm{Qa} / \mathrm{HK} / \mathrm{CSW} 106 / 01$ \\
\hline & A/guinea fowl/HK/NT897/01 & $\mathrm{H} 6 \mathrm{~N} 1$ & Gf/HK/NT897/01 \\
\hline & A/chicken/HK/SF3/01 & $\mathrm{H} 6 \mathrm{~N} 1$ & $\mathrm{Ck} / \mathrm{HK} / \mathrm{SF} 3 / 01$ \\
\hline & A/chicken/HK/SF4/01 & H6N1 & Ck/HK/SF4/01 \\
\hline & A/silky chicken/HK/AP46/01 & H6N2 & $\mathrm{Sc} / \mathrm{HK} / \mathrm{AP} 46 / 01$ \\
\hline \multirow{4}{*}{2002 isolates } & A/quail/HK/YU404/02 & H6N1 & Qa/HK/YU404/02 \\
\hline & A/quail/HK/YU421/02 & $\mathrm{H} 6 \mathrm{~N} 1$ & Qa/HK/YU421/02 \\
\hline & A/pheasant/HK/SSP44/02 & $\mathrm{H} 6 \mathrm{~N} 1$ & $\mathrm{Ph} / \mathrm{HK} / \mathrm{SSP} 44 / 02$ \\
\hline & A/guinea fowl/HK/SSP99/02 & H6N2 & Gf/HK/SSP99/02 \\
\hline \multirow{4}{*}{2003 isolates } & A/pigeon/HK/WF47/03 & H6N1 & $\mathrm{Pg} / \mathrm{HK} / \mathrm{WF} 47 / 03$ \\
\hline & A/chukkar/HK/SF126/03 & H6N1 & Ch/HK/SF126/03 \\
\hline & A/chukkar/HK/SF164/03 & $\mathrm{H} 6 \mathrm{~N} 1$ & Ch/HK/SF164/03 \\
\hline & A/chukkar/HK/CSW595/03 & H6N1 & Ch/HK/CSW595/03 \\
\hline
\end{tabular}

a The letters in the strain identifiers relate to market of isolation, that is, all viruses with identifiers SSP were isolated from the same market.

determine whether similar antigenic changes have occurred in H6 viruses in Hong Kong, we characterized the antigens of recent isolates by using $\mathrm{HI}$ tests. The $\mathrm{H} 6$ influenza viruses isolated in Hong Kong reacted with hyperimmune goat antisera raised against $\mathrm{A} /$ turkey/Massachusetts/1/65 (H6N2) (Ty/MA/1/65), hyperimmune rabbit antisera raised against A/shearwater/Australia/1/72 (H6N5) (Sh/Aus/1/72), and postinfection chicken antisera against $\mathrm{A} /$ teal/Hong Kong/W312/97 (H6N1) (Tl/HK/W312/97), A/quail/Hong Kong/YU1654/00 (H6N1) (Qa/HK/YU1654/00), A/quail/ Hong Kong/YU39/01 (H6N1) (Qa/HK/YU39/01), and A/ duck/Shantou/5540/01 (H6N2) (Dk/ST/5540/01) (Table 2). The antisera against Ty/MA/1/65 and Sh/Aus/1/72 were broadly reactive against all recent $\mathrm{H} 6$ viruses, as were antisera to Qa/HK/YU39/01 and Dk/ST/5540/01. All 2002 and 2003 isolates were antigenically indistinguishable from other viruses isolated during the same year whereas some heterogeneity existed among the 2001 isolates. Although there were detectable differences in reactivity patterns to antiserum against Qa/HK/YU39/01 between viruses of subsequent years, the H6 viruses of 2001, 2002, and 2003 represented a relatively antigenically homogeneous group of viruses. They had, however, changed in comparison to $\mathrm{Tl} / \mathrm{HK} / \mathrm{W} 312 / 97$, particularly in reactivity to antisera against Ty/MA/1/65 and Sh/Aus/1/72.

3.3. Genetic Analysis of the HA and NA Genes. The full-length HA sequences of the $18 \mathrm{H} 6$ influenza viruses were determined to analyze their phylogenetic relationships (Figure 1). The HA gene of contemporary H6 influenza viruses isolated from terrestrial poultry had an open reading frame of $1704 \mathrm{bp}$ that encodes a precursor protein of 567 amino acids. The insertion of a conserved aspartic acid between positions 144 and 145 (H3 numbering) of the precursor polypeptides distinguishes the contemporary terrestrial poultry viruses from aquatic bird viruses. All H6 isolates possessed the typical nonpathogenic sequence PQIETR/G at the HA cleavage site [26-28]. The homology between the HA nucleotide sequences of the contemporary isolates and that of $\mathrm{Tl} / \mathrm{HK} / \mathrm{W} 312 / 97$ ranged from $96 \%$ to $98 \%$. The two strains isolated from chicken in $2001(\mathrm{Ck} / \mathrm{HK} / \mathrm{SF} 3 / 01$ and $\mathrm{Ck} / \mathrm{HK} / \mathrm{SF} 4 / 01$ ) were typical of other $\mathrm{H} 6$ viruses within the terrestrial host clade.

In addition to the HA genes, the NA genes of all $18 \mathrm{H} 6$ isolates were sequenced. The N1NA genes from 14 virus isolates from domestic poultry, including the two isolates from chicken, belonged to the cluster represented by $\mathrm{Tl} / \mathrm{HK} / \mathrm{W} 312 / 97$. This cluster was distinguishable from that containing A/goose/Guandong/1/96-like (H5N1) N1NA genes. The remaining two N1NA genes, which were from two of the 2001 isolates $(\mathrm{Qa} / \mathrm{HK} / \mathrm{FB} 611 / 01$ and $\mathrm{Qa} / \mathrm{HK} / \mathrm{FB} 801 / 01)$, were slightly different from those of the Tl/HK/W312/97-like N1NA cluster and instead were more similar to that of A/quail/Hong Kong/1721-20/99.

Alignment analysis revealed a 19-amino acid deletion from the stalk region of the N1NAs of all contemporary terrestrial isolates. This deletion is characteristic of the $\mathrm{H} 6 \mathrm{~N} 1$ viruses isolated in the region after 1997 [18]. Unexpectedly, two of the contemporary H6 viruses isolated from domestic poultry contained N2 genes. The N2NA gene of Sc/HK/AP46/01 was similar to that of Qa/HK/G1/97like (H9N2) viruses (98\% identity to A/HK/1074/99); the high degree of similarity suggests that Sc/HK/AP46/01 was a reassortant derived from cocirculating $\mathrm{H} 6 \mathrm{~N} 1$ and $\mathrm{H} 9 \mathrm{~N} 2$ viruses. The N2NA gene of Gf/HK/SSP99/02 did not belong to the $\mathrm{Qa} / \mathrm{HK} / \mathrm{G} 1 / 97-$ like (H9N2) lineage but instead to 
TABLe 2: Antigenic analysis of H6 influenza viruses by hemagglutinin inhibition.

\begin{tabular}{|c|c|c|c|c|c|c|}
\hline \multirow{3}{*}{ Virus } & \multicolumn{6}{|c|}{ Titer $^{\mathrm{a}}$ for } \\
\hline & \multicolumn{2}{|c|}{ Hyperimmune rabbit antisera against } & \multicolumn{4}{|c|}{ Postinfection chicken antisera against } \\
\hline & Ty/MA/1/65 & Sh/Aus/1/72 & Tl/HK/W312/97 & Qa/HK/YU1564/00 & Qa/HK/YU39/01 & Dk/Shantou/5540/01 \\
\hline \multicolumn{7}{|l|}{ Reference strains } \\
\hline Ty/MA/1/65 & 2560 & 5120 & $<$ & 640 & 80 & 2560 \\
\hline $\mathrm{Sh} / \mathrm{Aus} / 1 / 72$ & 80 & 2560 & $<$ & $<$ & $<$ & $<$ \\
\hline Tl/HK/W312/97 & 80 & 160 & 2560 & 2560 & 640 & $<$ \\
\hline Qa/HK/YU1654/00 & 1280 & $<$ & 320 & 2560 & 80 & 320 \\
\hline $\mathrm{Qa} / \mathrm{HK} / \mathrm{YU} 39 / 01$ & 160 & 640 & 40 & 320 & 2560 & 80 \\
\hline Dk/Shantou/5540/01 & 320 & 320 & $<$ & $<$ & $<$ & 1280 \\
\hline \multicolumn{7}{|l|}{2001 isolates } \\
\hline Qa/HK/FB611/01 & 1280 & 2560 & 2560 & 2560 & 640 & 160 \\
\hline $\mathrm{Qa} / \mathrm{HK} / \mathrm{FB} / 801 / 01$ & 2560 & 5120 & 2560 & 5120 & 640 & 160 \\
\hline Qa/HK/SF104/01 & 5120 & 5120 & 2560 & 5120 & 5120 & 80 \\
\hline Qa/HK/FY119/01 & 1280 & 2560 & 640 & 2560 & 320 & 160 \\
\hline Qa/HK/NT342/01 & 1280 & 2560 & 640 & 2560 & 320 & 160 \\
\hline Qa/HK/CSW106/01 & 5120 & 5120 & 2560 & 5120 & 5120 & 80 \\
\hline Gf/HK/NT897/01 & 2560 & 5120 & 2560 & 5120 & 640 & 160 \\
\hline $\mathrm{Ck} / \mathrm{HK} / \mathrm{SF} 3 / 01$ & 5120 & 5120 & 640 & 5120 & 320 & 160 \\
\hline $\mathrm{Ck} / \mathrm{HK} / \mathrm{SF} 4 / 01$ & 5120 & 5120 & 640 & 5120 & 320 & 160 \\
\hline Sc/HK/AP46/01 & 2560 & 5120 & 1280 & 5120 & 320 & 160 \\
\hline \multicolumn{7}{|l|}{2002 isolates } \\
\hline Qa/HK/YU404/02 & 2560 & 2560 & 640 & 5120 & 640 & 160 \\
\hline $\mathrm{Qa} / \mathrm{HK} / \mathrm{YU} 421 / 02$ & 5120 & 5120 & 1280 & 5120 & 640 & 160 \\
\hline $\mathrm{Ph} / \mathrm{HK} / \mathrm{SSP} 44 / 02$ & 1280 & 5120 & 2560 & 2560 & 640 & 160 \\
\hline Gf/HK/SSP99/02 & 5120 & 5120 & 2560 & 5120 & 320 & 160 \\
\hline \multicolumn{7}{|l|}{2003 isolates } \\
\hline $\mathrm{Pg} / \mathrm{HK} / \mathrm{WF} 47 / 03$ & 2560 & 5120 & 640 & 5120 & 160 & 80 \\
\hline Ch/HK/SF126/03 & 2560 & 2560 & 640 & 2560 & 80 & 160 \\
\hline $\mathrm{Ch} / \mathrm{HK} / \mathrm{SF} 164 / 03$ & 2560 & 2560 & 640 & 2560 & 80 & 80 \\
\hline Ch/HK/CSW595/03 & 2560 & 2560 & 640 & 2560 & 80 & 80 \\
\hline
\end{tabular}

Ty: turkey; MA: Massachusetts; Sh: shearwater; Aus: Australia; Tl: teal; HK: Hong Kong; Qa: quail; Ph: pheasant; Dk: duck; Gf: guinea fowl; Sc: silky chicken;

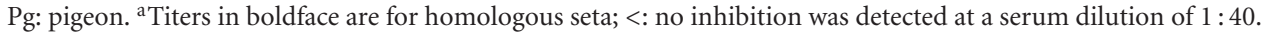

a lineage represented by recent duck H9N2 isolates; this finding suggests reassortment between H6N1 viruses and aquatic bird viruses.

3.4. Genetic Analysis of Internal Genes. In 1998 and 1999, the H6N1 viruses isolated from the Hong Kong markets were genetically stable and were of the same genetic lineage [18]. To determine whether the stability of H6 viruses has continued since 1999, we analyzed partial sequences for each of the remaining genes from the isolated H6 viruses. Phylogenetic analysis of the PA polymerase (PA) gene revealed that, after 2001, reassortment occurred not only with NA genes but also with internal genes. PA genes from all nine viruses isolated in 2001 as well as those of Qa/HK/YU404/02, and Qa/HK/YU421/02 were similar to Tl/HK/W312/97-like viruses. The PA genes of $\mathrm{Ph} / \mathrm{HK} / \mathrm{SSP} 44 / 02$, Gf/HK/SSP99/02, and all of the 2003 isolates showed high homology to those of $\mathrm{H} 5 \mathrm{~N} 1$ viruses isolated from domestic poultry in
2000 and 2001. Also belonging to this lineage were the $\mathrm{H} 5 \mathrm{~N} 1$ viruses isolated from humans in Hong Kong in 2003 [29, 30]. The NP gene segments of Ph/HK/SSP44/02 and all of the 2003 isolates were distinct from that of the Tl/HK/W312/97-like lineage, as were the NS gene segments of $\mathrm{Ph} / \mathrm{HK} / \mathrm{SSP} 44 / 02$, Gf/HK/SSP99/02 and all of the 2003 isolates. These NP and NS gene segments were most similar to those of Dk/HK/Y280/97-like viruses (H9N2). The NP and NS gene segments of A/pheasant/HK/FY294/00 (H6N1) also clustered with those of Dk/HK/Y280/97-like viruses; this clustering indicated that the reassortment events between H6 and H9 viruses had happened as early as 2000 . Although there were minor differences, the remaining gene segments (PB2, PB1, and $\mathrm{M}$ ) of the $\mathrm{H} 6$ viruses isolated from domestic poultry belonged to the Tl/HK/W312/97-like lineage (Table 3 ).

3.5. DDBJ Accession Numbers. The nucleotide sequences for 18 H6 strains presented in this paper have been submitted 
TABLE 3: Genotyping of H6 subtype influenza viruses isolated in southeastern China (2001-2003).

\begin{tabular}{|c|c|c|c|c|c|c|c|c|}
\hline \multirow[b]{2}{*}{ Virus } & \multicolumn{8}{|c|}{ Gene segment ${ }^{\mathrm{a}}$} \\
\hline & PB2 & $\mathrm{PB} 1$ & PA & $\mathrm{HA}$ & NP & NA & $\mathrm{M}$ & NS \\
\hline Qa/HK/FB611/01 & $\mathrm{W}$ & $\mathrm{W}$ & $\mathrm{W}$ & $\mathrm{W}$ & $\mathrm{W}$ & $\mathrm{W}$ & $\mathrm{W}$ & $\mathrm{W}$ \\
\hline $\mathrm{Qa} / \mathrm{HK} / \mathrm{FB} / 801 / 01$ & $\mathrm{~W}$ & $\mathrm{~W}$ & $\mathrm{~W}$ & $\mathrm{~W}$ & $\mathrm{~W}$ & $\mathrm{~W}$ & $\mathrm{~W}$ & $\mathrm{~W}$ \\
\hline Qa/HK/SF104/01 & W & W & $\mathrm{W}$ & $\mathrm{W}$ & $\mathrm{W}$ & $\mathrm{W}$ & $\mathrm{W}$ & $\mathrm{W}$ \\
\hline Qa/HK/NT342/01 & $\mathrm{W}$ & $\mathrm{W}$ & $\mathrm{W}$ & $\mathrm{W}$ & $\mathrm{W}$ & $\mathrm{W}$ & $\mathrm{W}$ & $\mathrm{W}$ \\
\hline Qa/HK/NT342/01 & $\mathrm{W}$ & $\mathrm{W}$ & $\mathrm{W}$ & $\mathrm{W}$ & $\mathrm{W}$ & $\mathrm{W}$ & $\mathrm{W}$ & $\mathrm{W}$ \\
\hline Qa/HK/CSW106/01 & $\mathrm{W}$ & $\mathrm{W}$ & $\mathrm{W}$ & $\mathrm{W}$ & $\mathrm{W}$ & $\mathrm{W}$ & $\mathrm{W}$ & $\mathrm{W}$ \\
\hline Gf/HK/NT897/01 & W & W & $\mathrm{W}$ & $\mathrm{W}$ & $\mathrm{W}$ & $\mathrm{W}$ & $\mathrm{W}$ & $\mathrm{W}$ \\
\hline $\mathrm{Ck} / \mathrm{HK} / \mathrm{SF} 3 / 01$ & W & W & W & W & W & W & $\mathrm{W}$ & $\mathrm{W}$ \\
\hline Ck/HK/SF4/01 & W & W & $\mathrm{W}$ & W & $\mathrm{W}$ & $\mathrm{W}$ & $\mathrm{W}$ & $\mathrm{W}$ \\
\hline Sc/HK/AP46/01 & W & W & $\mathrm{W}$ & $\mathrm{W}$ & $\mathrm{W}$ & G1 & $\mathrm{W}$ & $\mathrm{W}$ \\
\hline Qa/HK/YU404/02 & $\mathrm{W}$ & $\mathrm{W}$ & $\mathrm{W}$ & $\mathrm{W}$ & $\mathrm{W}$ & $\mathrm{W}$ & $\mathrm{W}$ & $\mathrm{W}$ \\
\hline Qa/HK/YU421/02 & W & W & W & $\mathrm{W}$ & W & W & $\mathrm{W}$ & $\mathrm{W}$ \\
\hline $\mathrm{Ph} / \mathrm{HK} / \mathrm{SSP} 44 / 02$ & $\mathrm{~W}$ & $\mathrm{~W}$ & $\mathrm{H} 5 \mathrm{~N} 1 / 01$ & $\mathrm{~W}$ & Y280 & $\mathrm{W}$ & $\mathrm{W}$ & Y280 \\
\hline Gf/HK/SSP99/02 & W & W & $\mathrm{H} 5 \mathrm{~N} 1 / 01$ & $\mathrm{~W}$ & $\mathrm{~W}$ & $\mathrm{H} 9 \mathrm{~N} 2 / 00$ & $\mathrm{~W}$ & Y280 \\
\hline $\mathrm{Pg} / \mathrm{HK} / \mathrm{WF} 47 / 03$ & $\mathrm{~W}$ & $\mathrm{~W}$ & $\mathrm{H} 5 \mathrm{~N} 1 / 01$ & $\mathrm{~W}$ & Y280 & $\mathrm{W}$ & $\mathrm{W}$ & $\mathrm{Y} 280$ \\
\hline Ch/HK/SF126/03 & W & $\mathrm{W}$ & $\mathrm{H} 5 \mathrm{~N} 1 / 01$ & $\mathrm{~W}$ & Y280 & $\mathrm{W}$ & $\mathrm{W}$ & Y280 \\
\hline Ch/HK/SF164/03 & $\mathrm{W}$ & W & $\mathrm{H} 5 \mathrm{~N} 1 / 01$ & $\mathrm{~W}$ & Y280 & W & $\mathrm{W}$ & Y280 \\
\hline Ch/HK/CSW595/03 & $\mathrm{W}$ & $\mathrm{W}$ & $\mathrm{H} 5 \mathrm{~N} 1 / 01$ & $\mathrm{~W}$ & Y280 & $\mathrm{W}$ & $\mathrm{W}$ & Y280 \\
\hline
\end{tabular}

W: A/teal/Hong Kong/W312/97-like; G1: A/quail/Hong Kong/G1/97-like; Y280: A/quail/Hong Kong/Y280/97-like; in 2001 H9N2/00 similar to H9N2 isolated from ducks in 2000. a Genotypes were established in light of the phylogenetic relationships.

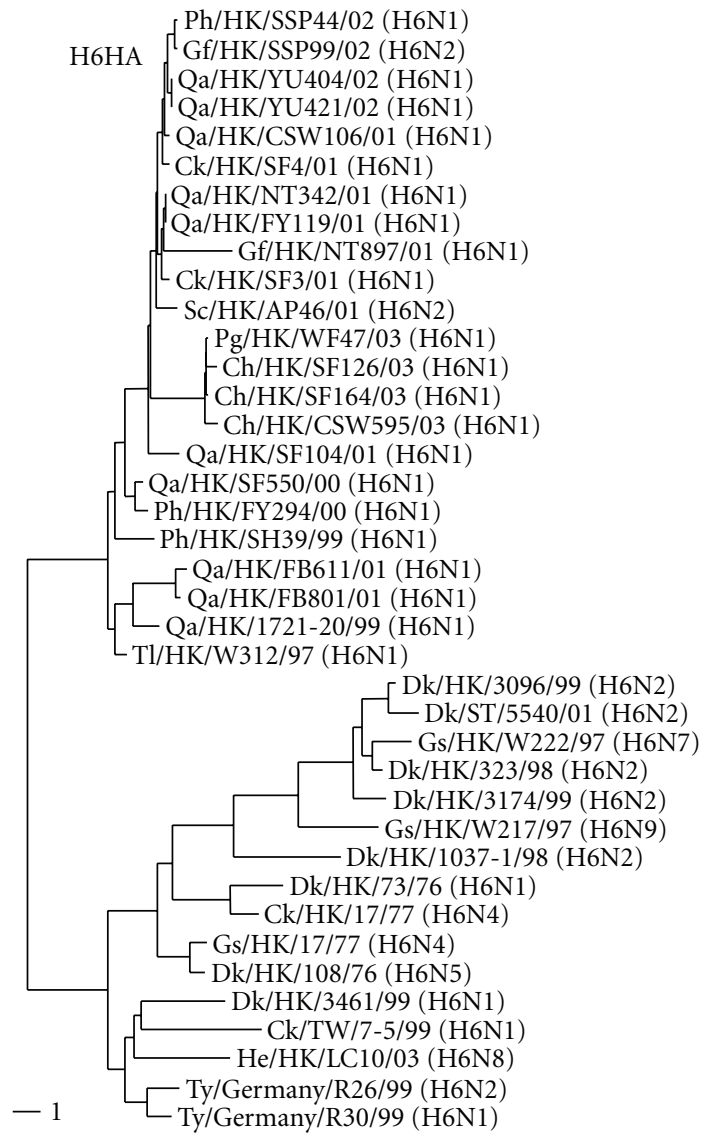

Figure 1: Phylogenetic analysis of the HA gene of Eurasian H6 influenza viruses. to DNA Data Bank of Japan (DDBJ) under the accession numbers AB586744 to AB586887.

3.6. Hemagglutination Activity. The receptor specificity of the HA is considered a likely determinant of host range for influenza viruses. Additionally, studies have shown that H9N2 viruses circulating in the Hong Kong live-bird markets have human virus-like receptor specificity [31]. To explore the receptor binding specificity of $\mathrm{Tl} / \mathrm{HK} / \mathrm{W} 312 / 97$ and contemporary $\mathrm{H} 6$ isolates, the ability of these viruses to agglutinate erythrocytes from chicken, horse, and guinea pig was measured. Tl/HK/W312/97 and recent $\mathrm{H} 6$ viruses from aquatic birds [Dk/ST/5540/01 (H6N2) and He/HK/LC10/03 (H6N8)] were uniform in their ability to agglutinate erythrocytes from all sources to similar levels (Table 4). Conversely, the recent $\mathrm{H} 6$ isolates from domestic poultry were able to agglutinate erythrocytes of chicken and guinea pig origin but not those from horse. The binding of the contemporary $\mathrm{H} 6$ isolates was similar to that of $\mathrm{Qa} / \mathrm{HK} / \mathrm{G} 1 / 97$, a virus with human virus-like receptor specificity [31]. These results demonstrate that the receptor binding properties of the recent $\mathrm{H} 6$ isolates from poultry have evolved from those of Tl/HK/W312/97.

3.7. Experimental Infection of Quail and Chickens. An increase in the number of $\mathrm{H} 6$ viruses isolated from chickens in the Hong Kong live-bird markets raised the possibility that the host range of these viruses was expanding and that they were adapting to chickens. To test this hypothesis, we determined for chicken and quail the 50\% infectious doses 
TABLE 4: Hemagglutinating activity with erythrocytes from different animals.

\begin{tabular}{|c|c|c|c|}
\hline & \multicolumn{3}{|c|}{ Hemagglutination with erythrocytes from } \\
\hline & Chicken & Horse & Guinea pig \\
\hline Tl/HK/W312/97 (H6N1) & 32 & 32 & 16 \\
\hline Qa/HK/FB611/01 (H6N1) & 32 & $<2$ & 16 \\
\hline Qa/HK/FB/801/01 (H6N1) & 32 & $<2$ & 16 \\
\hline Qa/HK/SF104/01 (H6N1) & 32 & $<2$ & 16 \\
\hline Qa/HK/NT342/01 (H6N1) & 32 & $<2$ & 16 \\
\hline Qa/HK/FY119/01 (H6N1) & 32 & $<2$ & 16 \\
\hline Qa/HK/CSW106/01 (H6N1) & 32 & $<2$ & 32 \\
\hline Gf/HK/NT897/01 (H6N1) & 32 & $<2$ & 32 \\
\hline Ck/HK/SF3/01 (H6N1) & 32 & $<2$ & 16 \\
\hline Ck/HK/SF4/01 (H6N1) & 32 & $<2$ & 16 \\
\hline Sc/HK/AP46/01 (H6N2) & 32 & $<2$ & 16 \\
\hline Dk/ST/5540/01 (H6N2) & 32 & 32 & 32 \\
\hline Qa/HK/YU404/02 (H6N1) & 32 & $<2$ & 16 \\
\hline Qa/HK/YU421/02 (H6N1) & 32 & $<2$ & 16 \\
\hline $\mathrm{Ph} / \mathrm{HK} / \mathrm{SSP} 44 / 02$ (H6N1) & 32 & $<2$ & 32 \\
\hline Gf/HK/SSP99/02 (H6N2) & 32 & $<2$ & 16 \\
\hline Pg/HK/WF47/03 (H6N1) & 32 & $<2$ & 16 \\
\hline Ch/HK/SF126/03 (H6N1) & 32 & $<2$ & 32 \\
\hline Ch/HK/SF164/03 (H6N1) & 32 & $<2$ & 16 \\
\hline Ch/HK/CSW595/03 (H6N1) & 32 & $<2$ & 16 \\
\hline He/HK/LC10/03 (H6N8) & 32 & 32 & 16 \\
\hline Qa/HK/G1/97 (H9N2) & 32 & $<2$ & 16 \\
\hline
\end{tabular}

TABle 5: Experimental infection of quails and chickens.

\begin{tabular}{|c|c|c|}
\hline Virus & $\mathrm{QID}_{50}^{\mathrm{a}}$ & $\mathrm{CID}_{50}^{\mathrm{a}}$ \\
\hline \multicolumn{3}{|l|}{ Domestic poultry isolates } \\
\hline \multicolumn{3}{|l|}{2001 isolates } \\
\hline Qa/HK/CSW106/01 (H6N1) & 3.00 & 5.00 \\
\hline Ck/HK/SF4/01 (H6N1) & 3.92 & 4.17 \\
\hline Sc/HK/AP46/01 (H6N2) & 3.63 & 5.08 \\
\hline \multicolumn{3}{|l|}{2002 isolates } \\
\hline $\mathrm{Ph} / \mathrm{HK} / \mathrm{SSP} 44 / 02$ (H6N1) & 2.20 & 4.58 \\
\hline Qa/HK/YU404/02 (H6N1) & 2.50 & 4.75 \\
\hline Gf/HK/SSP99/02 (H6N2) & 3.23 & 4.73 \\
\hline \multicolumn{3}{|l|}{2003 isolates } \\
\hline Ch/HK/CSW595/03 (H6N1) & 2.73 & 4.73 \\
\hline \multicolumn{3}{|l|}{ Aquatic wild-bird isolates } \\
\hline \multicolumn{3}{|l|}{2001 isolate } \\
\hline $\mathrm{Dk} / \mathrm{ST} / 5540 / 01$ (H6N2) & 2.6 & 6.48 \\
\hline \multicolumn{3}{|l|}{2003 isolate } \\
\hline He/HK/LC10/03 (H6N8) & 3.17 & 7.92 \\
\hline \multicolumn{3}{|l|}{ Reference strain } \\
\hline \multicolumn{3}{|l|}{1997 isolate } \\
\hline Tl/HK/W312/97 (H6N1) & 3.47 & 4.92 \\
\hline
\end{tabular}

${ }^{\mathrm{a}} \mathrm{QID}_{50}$ and $\mathrm{CID}_{50}$ indicate $50 \%$ quail and chicken infectious dose, respectively $\left(\log _{10} \mathrm{EID}_{50} / 0.1 \mathrm{ml}\right)$. Each titer was obtained from tracheal swabs of animals at 3-day postinoculation. of selected H6 viruses isolated from different host species. Virus titers were standardized to $10^{7.5}$ to $10^{8.0} \mathrm{EID}_{50} / 0.1 \mathrm{ml}$. Tl/HK/W312/97 and the domestic poultry H6 isolates from 2001, 2002, and 2003 were able to infect quail and chickens (Table 5), although in each case the $\mathrm{ID}_{50}$ was lower for quail than for chicken. None of the tested strains showed a markedly increased infectivity for chicken; the lack of an increase suggests that the contemporary H6 viruses, including those isolated from chickens, were not more adapted to chickens than was Tl/HK/W312/97.

3.8. Poultry-to-Poultry Transmission Experiment. The ability of a virus to replicate within a host does not always correspond to its ability to be transmitted between individuals of that host. The ability of the domestic poultry H6 viruses to grow in chickens upon experimental infection conflicts with the low rates of isolation from this host in the markets. To determine the role of transmission in this apparent contradiction, we assessed the ability of the H6 viruses to be transmitted from chicken to chicken and from quail to chicken. Although the H6 viruses we selected replicated in the inoculated animals, no virus was isolated from the animals in direct contact with infected birds (Table 6); this result shows that transmission of the $\mathrm{H} 6$ viruses to chickens is poor. In contrast, Qa/HK/CSW106/01, Ck/HK/SF4/01, and $\mathrm{Ph} / \mathrm{HK} / \mathrm{SSP} 44 / 02$ were efficiently transmitted from infected to contact quail (data not shown). These infection and 
TABLE 6: Experimental transmission of recent H6N1 viruses from quail to chicken and from chicken to chicken.

\begin{tabular}{|c|c|c|c|c|}
\hline \multirow{3}{*}{ Virus } & \multicolumn{4}{|c|}{ No. of positive trachea/total no. of birds [ $-\log _{10}\left(\mathrm{EID}_{50} / 0.1 \mathrm{ml}\right)$ for each bird] } \\
\hline & \multicolumn{2}{|c|}{ Quails to chickens } & \multicolumn{2}{|c|}{ Chickens to chickens } \\
\hline & Inoculated $^{\mathrm{a}}$ & Direct contact ${ }^{\mathrm{b}}$ & Inoculated ${ }^{\mathrm{a}}$ & Direct contact ${ }^{t}$ \\
\hline Qa/HK/CSW106/01 & $3 / 3(2.7,2.0,2.5)$ & $0 / 3$ & $3 / 3(3.0,2.0,2.3)$ & $0 / 3$ \\
\hline $\mathrm{Ck} / \mathrm{HK} / \mathrm{SF} 4 / 01$ & $3 / 3(2.0,1.5,2.7)$ & $0 / 3$ & $3 / 3(2.0,1.5,2.0)$ & $0 / 3$ \\
\hline $\mathrm{Qa} / \mathrm{HK} / \mathrm{YU} 404 / 02$ & $3 / 3(2.5,2.5,2.0)$ & $0 / 3$ & $3 / 3(1.0,2.3,2.5)$ & $0 / 3$ \\
\hline $\mathrm{Ph} / \mathrm{HK} / \mathrm{SSP} 44 / 02$ & $3 / 3(3.0,2.7,2.0)$ & $0 / 3$ & $3 / 3(2.3,2.0,2.7)$ & $0 / 3$ \\
\hline $\mathrm{Ch} / \mathrm{HK} / \mathrm{CSW} 595 / 03$ & $3 / 3(2.3,2.0,2.7)$ & $0 / 3$ & $3 / 3(2.3,1.5,2.5)$ & $0 / 3$ \\
\hline
\end{tabular}

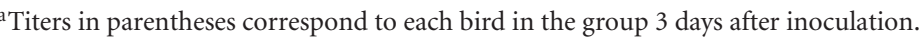

${ }^{\mathrm{b}}$ Tracheal swabs were collected and titrated 5 days and 7 days after being put with inoculated group.

transmission results suggest that the $\mathrm{H} 6$ viruses circulating in southeastern China have not adapted to chicken populations and are unlikely to do so without further genetic change.

\section{Discussion}

The outbreak of H5N1 influenza in 1997 prompted researchers to hypothesize that chickens have the capacity to act as an intermediate host for influenza virus in humans. In light of this possibility, the observation that the host range of $\mathrm{H} 6$ viruses within the Hong Kong live-bird markets might be increasing to include chickens caused concern. H5N1 and H9N2 viruses that had been circulating in poultry in Hong Kong have caused human infection $[7,8,13$, 14, 17]. H6N1 viruses have been cocirculating with these H5N1 and H9N2 viruses in Hong Kong but have not been isolated from humans, and these viruses appear to have remained genetically stable with regard to antigenic drift and reassortment [18]. The results of our study show that, although the $2003 \mathrm{H} 6$ viruses are not more adapted to chicken than are earlier isolates, H6 viruses in Hong Kong are evolving and reassorting with other viruses.

Antigenic and genetic analyses of the $\mathrm{H} 6$ influenza viruses isolated from domestic poultry in southeastern China from 2001 through 2003 provide convincing evidence that the $\mathrm{H} 6$ influenza viruses are reassorting with $\mathrm{H} 9 \mathrm{~N} 2, \mathrm{H} 5 \mathrm{~N} 1$, and other viruses in the region. Previous studies have suggested that $\mathrm{H} 9 \mathrm{~N} 2$ viruses have a two-way transmission between terrestrial and aquatic birds [32]. This two-way transmission resulted in the generation of multiple genotypes of H9N2 viruses containing internal genes of aquatic avian origin. It is unclear whether the same type of transmission is occurring with $\mathrm{H} 6 \mathrm{~N} 1$ viruses or whether they are acquiring aquatic bird genes from H9N2 or similar viruses. Further interspecies transmission of these reassortants to other hosts may subsequently occur. This pattern parallels the re-emergence of $\mathrm{H} 5 \mathrm{~N} 1$ influenza viruses in Hong Kong in 2001 during which multiple new genotypes were identified [33]. Although all H6 HA genes appear to be of the Tl/HK/W312/97 lineage, the result of HI assays indicate that despite a high level of genetic similarity, there has been a gradual decline in the reactivity of the recent isolates to serum raised against isolates collected in 2001.
The ability of the Tl/HK/W312/97-like H6N1 or H6N2 viruses to replicate and transmit in quail but not in chickens suggested that the removal of quail from the Hong Kong markets (accomplished in February 2002) would substantially affect the isolation rates of H6 viruses [25]. In 2001, 232 H6 viruses were isolated in the market but only 12 during 2002 and 9 in 2003 were isolated. This dramatic reduction in the isolation rate does indeed suggest that quail were playing an important role in maintaining $\mathrm{H} 6$ viruses within the markets. The comparatively small number of birds such as chukkas and pheasants in the markets corresponds with the small number of $\mathrm{H} 6$ viruses isolated since the removal of quail. The lack of efficient transmission of the $\mathrm{H} 6$ viruses to chicken under experimental conditions, however, conflicts with the isolation of these viruses from chicken in the markets. One possible explanation for this is the nature of the surveillance sampling. Many market samples are fecal samples taken from cages beneath a given species of bird. Although the isolates are likely from the species housed in the above cage, there is the possibility of environmental contamination. A second possibility relates to the controlled nature of the experimental infections. It is likely that the birds in the markets are under additional stresses exerted by temperature and other environmental factors in addition to the presence of other pathogens. Such stresses which are impossible to mimic in laboratory settings may increase the susceptibility of the birds to influenza infection. Regardless, our results showing the unlikely role of chicken as efficient hosts of $\mathrm{H} 6$ viruses in the Hong Kong market system suggest that H6 viruses are now maintained by species such as chukkas and pheasants but not by chickens. Correspondingly, it should be expected that their incidence will remain low unless further adaptation to the chicken host is achieved.

In addition to the reduction in isolation rates, the increase in the genetic diversity within the $\mathrm{H} 6$ viruses in the markets also corresponds with the removal of quail. Exactly what role quail may have had in maintaining a stable Tl/HK/W312/97-like lineage is uncertain. Reassortants were present as early as 2000, but Tl/HK/W312/97-like viruses were the dominant genotype. It could be speculated that the Tl/HK/W312/97-like viruses are more adapted for replication and transmission in quail than some of the reassortant viruses. Hence, while quail remained in the market Tl/HK/W312/97-like viruses predominated. The 
association of Qa/HK/G1/97 (H9N2)-like viruses, that share 6 gene segments in common with Tl/HK/W312/97, with quail would support this possibility. It is of course also possible that it is coincidence that links the removal of quail and the emergence of multiple genotypes. Studies on H9N2 [34] and H5N1 [12] isolates in the region have also revealed an increasing degree of genetic diversity within these viruses. A more sinister scenario for the increase in H6 diversity is that there was an across-the-board enhancement in the amount of genetic reassortment occurring in the domestic poultry viruses throughout Southeast Asia.

Although we were unable to detect an increase in the chicken infectivity of recent $\mathrm{H} 6$ viruses, some biologic differences to Tl/HK/W312/97 were seen. Similar to what has been described for H9N2 viruses [31], the contemporary $\mathrm{H} 6$ viruses have erythrocyte binding properties more reminiscent of human viruses. Human viruses, in contrast to avian viruses, are unable to bind to horse erythrocytes which contain primarily $\alpha 2-3$-linked sialic acids. Unlike the contemporary H6 viruses, Tl/HK/W312/97 has an avian virus-like binding pattern and retains the ability to bind to horse erythrocytes. Interestingly, the contemporary H6 viruses do not contain any of the amino acid changes in the HA that Matrosovich and colleagues associated with the human virus-like binding properties of the H9N2 viruses. Similarly, no correlation between predicted carbohydrate moieties and binding preferences of the $\mathrm{H} 6$ viruses was seen. It is interesting that both $\mathrm{H} 9$ and $\mathrm{H} 6$ viruses have evolved towards a human-like virus binding preference. The fact that it has occurred in distinct subtypes of influenza virus would strongly support a selective advantage accompaning the change. Exactly what environmental or host factor is driving the selective pressure is unclear.

The hypothesis that the host range of $\mathrm{H} 6$ viruses underwent expansion in the Hong Kong markets appears to be incorrect in view of our findings. $\mathrm{H} 6$ viruses do have the capacity to be maintained in chicken populations as demonstrated by the emergence of multiple genotypes of H6N2 virus in chicken in the United States [35-37]. What further molecular changes are required for establishment of the Hong Kong $\mathrm{H} 6$ viruses in chickens, if at all possible, is unknown. Although the removal of quail has reduced the H6 virus burden in the Hong Kong bird markets, there has been an abrupt and corresponding increase in the genetic diversity of these viruses. It is unclear what effect this increase has on the continued presence and importance of these viruses for animal and human health.

\section{Acknowledgments}

These studies were supported by Grant AI95357 from the National Institute of Allergy and Infectious Diseases, by Cancer Center Support (CORE) Grant CA-21765 from the National Institutes of Health, and by the American Lebanese Syrian Associated Charities (ALSAC). The authors thank Yolanda Sims for excellent technical assistance, Christoph Scholtissek for helpful comments, and Dr. Amy Frazier for editorial assistance.

\section{References}

[1] Y. Kawaoka, S. Krauss, and R. G. Webster, "Avian-to-human transmission of the PB1 gene of influenza A viruses in the 1957 and 1968 pandemics," Journal of Virology, vol. 63, no. 11, pp. 4603-4608, 1989.

[2] C. Scholtissek, W. Rohde, V. Von Hoyningen, and R. Rott, "On the origin of the human influenza virus subtypes H2N2 and H3N2," Virology, vol. 87, no. 1, pp. 13-20, 1978.

[3] J. K. Taubenberger, A. H. Reid, A. E. Krafft, K. E. Bijwaard, and T. G. Fanning, "Initial genetic characterization of the 1918 'Spanish' influenza virus," Science, vol. 275, no. 5307, pp. 1793-1796, 1997.

[4] R. G. Webster, W. J. Bean, O. T. Gorman, T. M. Chambers, and Y. Kawaoka, "Evolution and ecology of influenza A viruses," Microbiological Reviews, vol. 56, no. 1, pp. 152-179, 1992.

[5] K. F. Shortridge and C. H. Stuart-Harris, "An influenza epicentre?” The Lancet, vol. 2, no. 8302, pp. 812-813, 1982.

[6] E. C. J. Claas, A. D. M. E. Osterhaus, R. Van Beek et al., "Human influenza A H5N1 virus related to a highly pathogenic avian influenza virus," The Lancet, vol. 351, no. 9101, pp. 472-477, 1998.

[7] K. Subbarao, A. Klimov, J. Katz et al., "Characterization of an avian influenza A ( $\mathrm{H} 5 \mathrm{~N} 1)$ virus isolated from a child with a fatal respiratory illness," Science, vol. 279, no. 5349, pp. 393396, 1998.

[8] K. Y. Yuen, P. K. S. Chan, M. Peiris et al., "Clinical features and rapid viral diagnosis of human disease associated with avian influenza A H5N1 virus," The Lancet, vol. 351, no. 9101, pp. 467-471, 1998.

[9] K. R. Cameron, V. Gregory, J. Banks et al., "H9N2 subtype influenza A viruses in poultry in Pakistan are closely related to the H9N2 viruses responsible for human infection in Hong Kong," Virology, vol. 278, no. 1, pp. 36-41, 2000.

[10] Y. Guo, J. Dong, M. Wang, Y. Zhang, J. Guo, and K. Wu, "Characterization of hemagglutinin gene of influenza a virus subtype H9N2," Chinese Medical Journal, vol. 114, no. 1, pp. 76-79, 2001.

[11] P. J. Homme and B. C. Easterday, "Avian influenza virus infections. IV. Response of pheasants, ducks, and geese to influenza A-turkey-Wisconsin-1966 virus," Avian Diseases, vol. 14, no. 2, pp. 285-290, 1970.

[12] Y. Guan, K. F. Shortridge, S. Krauss, and R. G. Webster, "Molecular characterization of H9N2 influenza viruses: were they the donors of the "internal" genes of H5N1 viruses in Hong Kong?" Proceedings of the National Academy of Sciences of the United States of America, vol. 96, no. 16, pp. 9363-9367, 1999.

[13] Y. P. Lin, M. Shaw, V. Gregory et al., "Avian-to-human transmission of H9N2 subtype influenza A viruses: relationship between H9N2 and H5N1 human isolates," Proceedings of the National Academy of Sciences of the United States of America, vol. 97, no. 17, pp. 9654-9658, 2000.

[14] M. Peiris, K. Y. Yuen, C. W. Leung et al., "Human infection with influenza H9N2," The Lancet, vol. 354, no. 9182, pp. 916917, 1999.

[15] J. S. M. Peiris, Y. Guan, D. Markwell, P. Ghose, R. G. Webster, and K. F. Shortridge, "Cocirculation of avian H9N2 and contemporary "human" $\mathrm{H} 3 \mathrm{~N} 2$ influenza A viruses in pigs in southeastern China: potential for genetic reassortment?" Journal of Virology, vol. 75, no. 20, pp. 9679-9686, 2001.

[16] E. Hoffmann, J. Stech, I. Leneva et al., "Characterization of the influenza A virus gene pool in avian species in southern China: 
was $\mathrm{H} 6 \mathrm{~N} 1$ a derivative or a precursor of $\mathrm{H} 5 \mathrm{~N} 1$ ?" Journal of Virology, vol. 74, no. 14, pp. 6309-6315, 2000.

[17] K. F. Shortridge, N. N. Zhou, Y. Guan et al., "Characterization of avian H5N1 influenza viruses from poultry in Hong Kong," Virology, vol. 252, no. 2, pp. 331-342, 1998.

[18] P. S. Chin, E. Hoffmann, R. Webby et al., "Molecular evolution of $\mathrm{H} 6$ influenza viruses from poultry in southeastern China: prevalence of $\mathrm{H} 6 \mathrm{~N} 1$ influenza viruses possessing seven A/Hong Kong/156/97 (H5N1)-like genes in poultry," Journal of Virology, vol. 76, no. 2, pp. 507-516, 2002.

[19] H. Kida, L. E. Brown, and R. G. Webster, "Biological activity of monoclonal antibodies to operationally defined antigenic regions on the hemagglutinin molecule of A/Seal/Massachusetts/1/80 (H7N7) influenza virus," Virology, vol. 122, no. 1, pp. 38-47, 1982.

[20] E. Hoffmann, J. Stech, Y. Guan, R. G. Webster, and D. R. Perez, "Universal primer set for the full-length amplification of all influenza A viruses," Archives of Virology, vol. 146, no. 12, pp. 2275-2289, 2001.

[21] J. D. Thompson, D. G. Higgins, and T. J. Gibson, "CLUSTAL $\mathrm{W}$ : improving the sensitivity of progressive multiple sequence alignment through sequence weighting, position-specific gap penalties and weight matrix choice," Nucleic Acids Research, vol. 22, no. 22, pp. 4673-4680, 1994.

[22] C. Macken, H. Lu, J. Goodman, and C. A. Boyle, "The value of a database in surveillance and vaccine selection," in Options for the Control of Influenza IV, A. D. M. E. Osterhaus, N. Cox, and A. W. Hampson, Eds., pp. 103-106, Elsevier Science, 2001.

[23] T. Saito, W. Lim, T. Suzuki et al., "Characterization of a human H9N2 influenza virus isolated in Hong Kong," Vaccine, vol. 20, no. 1-2, pp. 125-133, 2001.

[24] T. Ito, Y. Suzuki, L. Mitnaul, A. Vines, H. Kida, and Y. Kawaoka, "Receptor specificity of influenza A viruses correlates with the agglutination of erythrocytes from different animal species," Virology, vol. 227, no. 2, pp. 493-499, 1997.

[25] D. R. Perez, W. Lim, J. P. Seiler et al., "Role of quail in the interspecies transmission of $\mathrm{H} 9$ influenza a viruses: molecular changes on HA that correspond to adaptation from ducks to chickens," Journal of Virology, vol. 77, no. 5, pp. 3148-3156, 2003.

[26] F. X. Bosch, W. Garten, H. D. Klenk, and R. Rott, "Proteolytic cleavage of influenza virus hemagglutinins: primary structure of the connecting peptide between HA1 and HA2 determines proteolytic cleavability and pathogenicity of avian influenza viruses," Virology, vol. 113, no. 2, pp. 725-735, 1981.

[27] A. Stieneke-Grober, M. Vey, H. Angliker et al., "Influenza virus hemagglutinin with multibasic cleavage site is activated by furin, a subtilisin-like endoprotease," EMBO Journal, vol. 11, no. 7, pp. 2407-2414, 1992.

[28] R. G. Webster and R. Rott, "Influenza virus a pathogenicity: the pivotal role of hemagglutinin," Cell, vol. 50, no. 5, pp. 665$666,1987$.

[29] "Update: influenza activity_United States and worldwide, 2002-03 season, and composition of the 2003-04 influenza vaccine," Morbidity and Mortality Weekly Report, vol. 52, no. 22, pp. 516-521, 2003.

[30] "Update: Influenza activity-United States, 2002-03 [corrected] season," Morbidity and Mortality Weekly Report, vol. 51, no. 48, pp. 1095-1107, 2002.

[31] M. N. Matrosovich, S. Krauss, and R. G. Webster, "H9N2 influenza A viruses from poultry in Asia have human viruslike receptor specificity," Virology, vol. 281, no. 2, pp. 156-162, 2001.
[32] K. S. Li, K. M. Xu, S. M. Peiris et al., "Characterization of H9 subtype influenza viruses from the ducks of Southern China: a candidate for the next influenza pandemic in humans?" Journal of Virology, vol. 77, no. 12, pp. 6988-6994, 2003.

[33] Y. Guan, J. S. M. Peiris, A. S. Lipatov et al., "Emergence of multiple genotypes of $\mathrm{H} 5 \mathrm{~N} 1$ avian influenza viruses in Hong Kong SAR," Proceedings of the National Academy of Sciences of the United States of America, vol. 99, no. 13, pp. 8950-8955, 2002.

[34] Y. K. Choi, H. Ozaki, R. J. Webby et al., "Continuing evolution of H9N2 influenza viruses in Southeastern China," Journal of Virology, vol. 78, no. 16, pp. 8609-8614, 2004.

[35] H. Kinde, D. H. Read, B. M. Daft et al., "The occurrence of avian influenza A subtype H6N2 in commercial layer flocks in Southern California (2000-02): clinicopathologic findings," Avian Diseases, vol. 47, pp. 1214-1218, 2003.

[36] R. J. Webby, P. R. Woolcock, S. L. Krauss, and R. G. Webster, "Reassortment and interspecies transmission of North American H6N2 influenza viruses," Virology, vol. 295, no. 1, pp. 44 53, 2002.

[37] P. R. Woolcock, D. L. Suarez, and D. Kuney, "Lowpathogenicity avian influenza virus (H6N2) in chickens in California, 2000-02," Avian Diseases, vol. 47, pp. 872-881, 2003. 


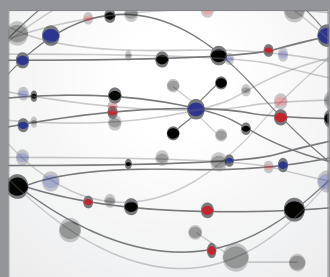

The Scientific World Journal
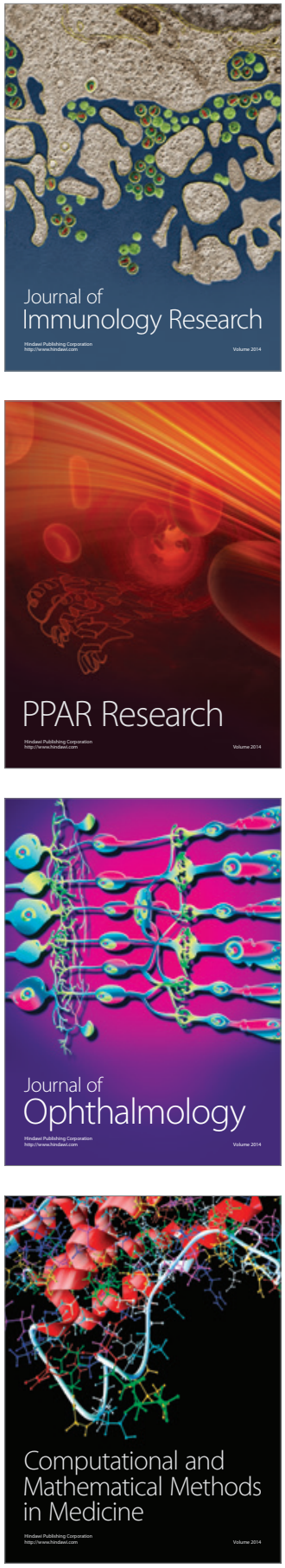

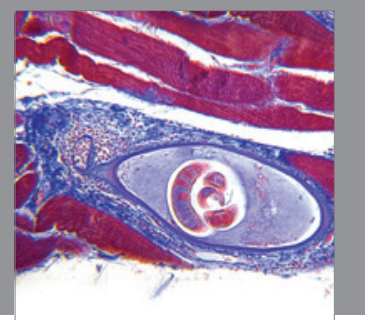

Gastroenterology

Research and Practice
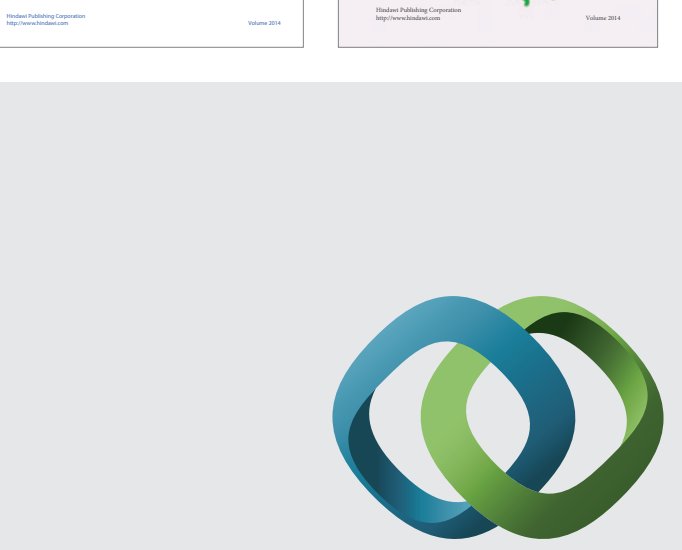

\section{Hindawi}

Submit your manuscripts at

http://www.hindawi.com
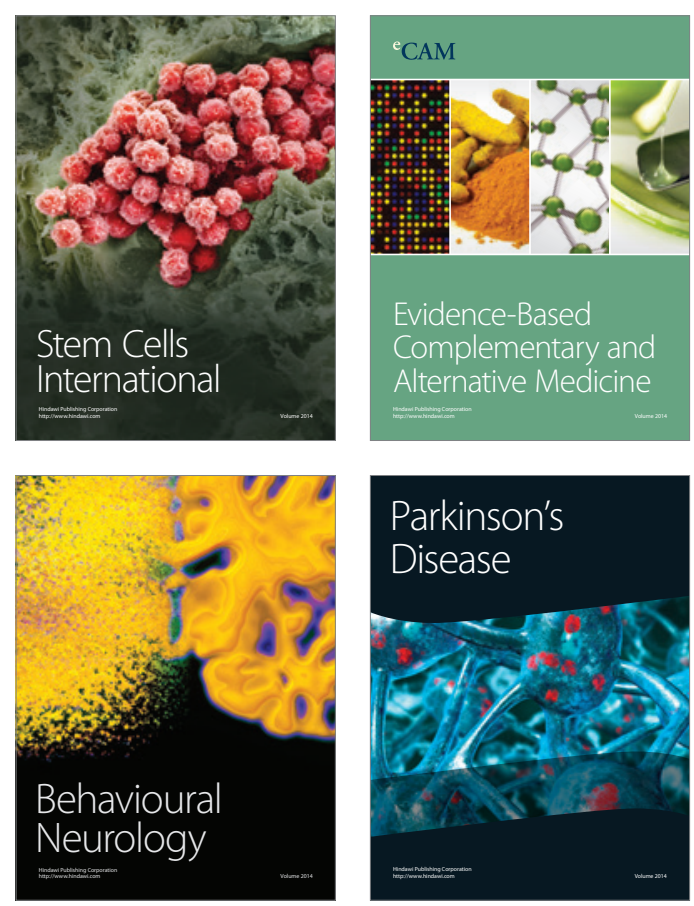

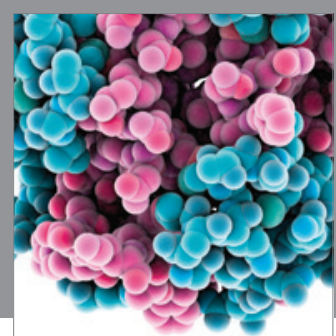

Journal of
Diabetes Research

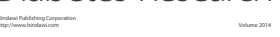

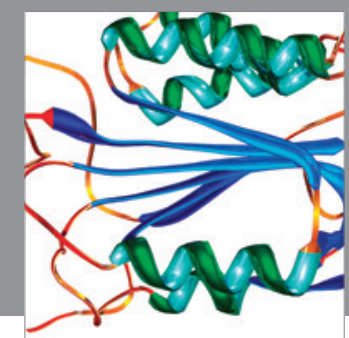

Disease Markers
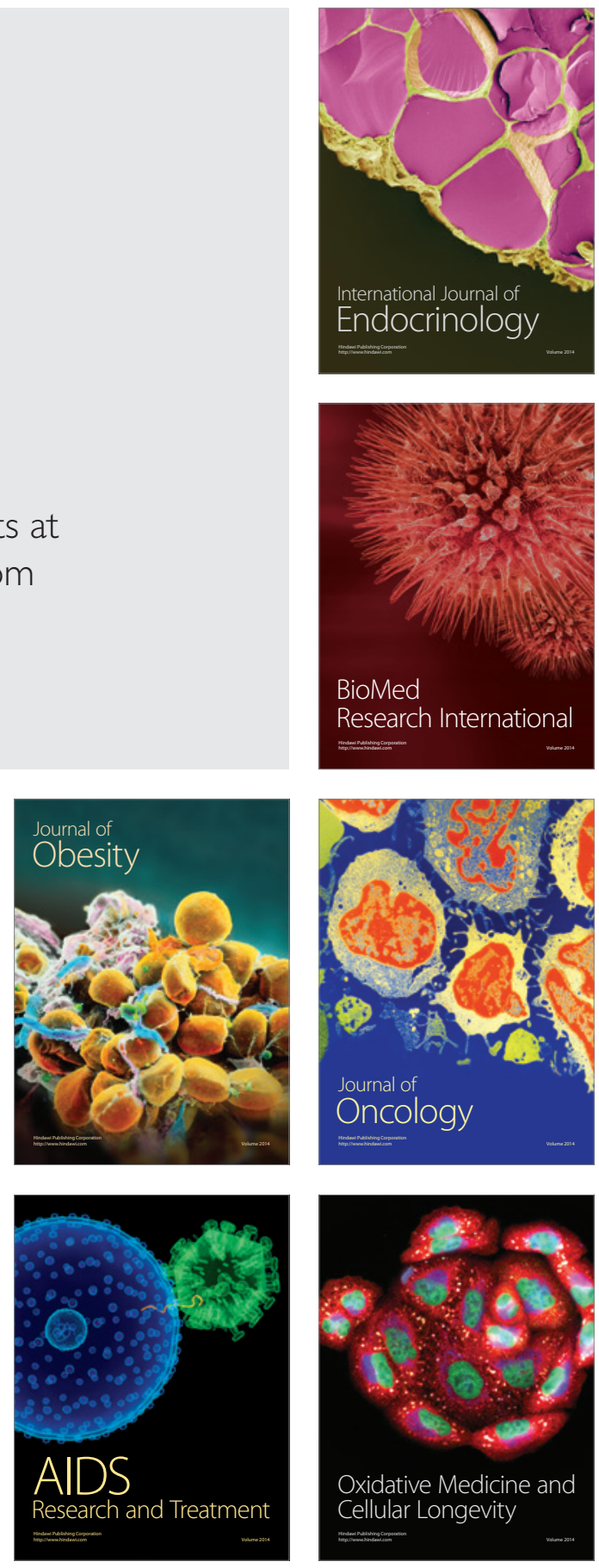